\title{
New Mexico
}

National Cancer Institute

\section{Source}

National Cancer Institute. New Mexico. NCI Thesaurus. Code C43504.

A state in the southwestern United States. Its capital is Santa Fe. 